\title{
What drives alignment during text chat with a peer vs. a tutor? Insights from cued interviews and eye-tracking
}

Marije Michel (Lancaster University, UK; Groningen University, NL); m.c.michel@rug.nl $\&$

Breffni O'Rourke (Trinity College Dublin, IR)

\section{Introduction}

The authors conceived the study on which this article reports at [event redacted]. Stephen Bax, at the time just about to take up a professorship at OU, was also a contributor to the seminar, and presented his justly celebrated work exploring cognitive processes of readingtest takers using eye-tracking (Bax, 2013).

On presenting our embryonic study design, we were encouraged by the reaction to the idea from Stephen Bax and the other participants to proceed with the work, and we owe a debt to him for that reason. But more generally, like many other colleagues in the field, we have been inspired by Stephen's idea of the normalisation of technology in language pedagogy (Bax, 2003; Chambers \& Bax, 2006). Online communication is perhaps a paradigm case of normalisation - at least prospective normalisation: at one time an everyday activity principally among professionals like academics and scientists, later an esoteric interest for a small community of researchers into Computer Assisted Language Learning (CALL), technology-mediated communication has become pervasive in the lives of many, if not yet in language education (Plonsky \& Ziegler, 2016). We hope that this study will make a contribution towards understanding the potential role of text-based communication as a common, if not yet fully normalised pedagogical activity, and the role of eye-tracking in researching it; and that it will stand as a small tribute to Stephen Bax's inspiring work. 


\section{Literature review}

\subsection{Written digitally-mediated communication: Text chat and second language (L2)}

\section{learning}

When we introduce a mediating tool into an activity, we do not just make the activity more efficient; we transform it (Wertsch, 2002; Engeström, 2014). This is one way of understanding text-based synchronous computer-mediated communication (SCMC, henceforth "text chat"). In a naïve view it is simply talk by other means, but when we change modality, swapping speech for text, we change many other things too: the rate of information creation and exchange; (“conversation in slow motion", Beauvois, 1992), our cognitive processing of individual utterances (both our own and our partners'; Chapelle, 2009), the fine detail of the discourse (e.g., O'Rourke, 2012). The properties of text chat may create challenges in processing on many levels (not least pragmatic processes such as determining intended propositional attitude, and discourse processes such as reconstructing cross-turn coherence); but they also create affordances for action and cognition which do not exist in speech. For instance, the persistent on-screen record of conversation may free up workingmemory resources for higher-level processing such as utterance planning. Long-term chat records may free the interlocutor from the obligation to commit information to long-term memory in parallel with the communicative event (Lai \& Zhao, 2006; Sauro \& Smith, 2010).

These and other affordances are potentially exploitable in second language learning. Research has focused, in particular, on how text chat may offer opportunities for focus on linguistic form in the course of meaningful communication which are not readily available in other communicative formats (see review by Ziegler, 2016). Such a focus is central to many theories of second language acquisition (SLA) and pedagogy, notably Schmidt's (1990) noticing hypothesis and the interaction hypothesis (Doughty \& Long, 2003; Long, 1996), which posit a key role for attention to the language produced by more expert interlocutors in 
meaning-focused communication (Gass \& Mackey, 2006). The persistent record of text supports longer and possibly deeper engagement with the form of interlocutors' contributions than is permitted by the rapidly fading phonological trace of oral utterances in working memory. Such scrutiny is facilitated by physical separation from the interlocutor and the overall slower pace of interaction (Gurzynski-Weiss \& Baralt, 2015; Sauro, 2011). From the point of view of production, chat users have more time for planning their utterances, have opportunities to revise them after drafting but before sending, and may re-read them after drafting while waiting for the interlocutor's next turn. The wait period also makes possible a kind of "browsing" of previous discourse which is less focussed on local, immediate requirements of turn processing, planning and production; this too may have benefits for noticing and, directly or indirectly, L2 learning (O'Rourke, 2012).

The growing interest in text chat in L2 acquisition and pedagogy is reflected in a meta-analysis by Lin, Huang, and Liou (2013) and Ziegler (2016), both of which found small but positive effects of SCMC. A more general research synthesis by Sauro (2011) identified the wide range of areas in which SCMC research has been conducted, encompassing grammatical competence (by far the most prevalent focus in the studies reviewed); the nature of L2 performance; and strategic, pragmatic, and discourse competence, among other areas. The more recent second-order synthesis by Plonsky and Ziegler (2016) generally confirms these earlier findings.

\subsection{Alignment: Definition}

A phenomenon of emerging interest within SCMC is that of alignment (Pickering \& Ferreira, 2008; Pickering \& Garrod, 2004, 2006). The behavioural facts are straightforward enough: interlocutors in conversation seem to implicitly converge on the use of particular structures and expressions. But this empirical observation underpins a rich theory of dialogic communication, the interactive-alignment theory, in which the cognitive-interactive 
mechanism of priming facilitates representational alignment at multiple levels, including linguistic representation (phonological, lexical, morphosyntactic) and semantic-conceptual models. Alignment in linguistic representations, manifested as spoken expressions, is claimed to give rise to alignment of mental states (Pickering \& Garrod, 2004, 2006).

Since priming, "whereby encountering an utterance that activates a particular representation makes it more likely that the person will subsequently produce an utterance that uses that representation" (Pickering \& Garrod, 2004, p. 173), is in this view fundamental to dialogic communication, it is assumed to be an automatic, cognitively efficient mechanism. But what then of dialogue in which one or both of the interlocutors are not fully competent in the language, as is the case for many L2 speakers? Does linguistic alignment occur, and if so, does it draw on the same automatic priming mechanism used in L1? These questions are addressed by Jackson (2017) and were conceptualised earlier by Costa, Pickering and Sorace (2008). The latter argue that observed linguistic alignment in dialogue involving at least one L2 speaker (henceforth "second language dialogue") may not be automatic, but can be a controlled and strategic process. Drawing on findings by Branigan et al. (2007), that participants aligned more when they believed their interlocutor was a computer than when they believed it was a human, Costa et al. (2008) state that "imitation can be affected by participants' beliefs under some circumstances, and moreover that beliefs about one's interlocutor's linguistic performance may be important" (p. 536).

Costa et al. (2008) predict that although there will be some automatic alignment in L2 conversations, other routes to alignment will also be used. They adduce various factors which, they conjecture, are likely to affect the degree of alignment exhibited by an L2 speaker with an L1 speaker versus an L2 speaker. At a less conscious level, in dialogue with a native speaker, L2 speakers are less likely to align with those words or structures that they are less familiar with or have less control over; and further, second-language interaction is 
more effortful and less automatic, which might impair the operation of automatic priming, hence alignment. At the level of conscious decisions, L2 speakers might deliberately avoid certain words or structures because they assess as too low their own familiarity or control of them; or they may favour words with cognates in their own L1 over synonyms used by their native-speaker interlocutor. Costa et al. (2008) give the example of a Spanish speaker using prison (cf. Spanish prisión) rather than the potentially primed jail used by an Englishspeaking interlocutor. An important factor promoting alignment, on the other hand, is the desire of the L2 speaker to learn the target language, using the L1 interlocutor as a model; and the re-use of recently-heard L1 terms as a form of hypothesis-testing, similar to copying L1 sources during L2 writing (Keck, 2014; Pennycook, 1996).

In L2-L2 conversation, Costa et al. (2008) point out that automatic alignment should be more prevalent the more closely related the L1s of the interlocutors, since cross-linguistic transfer is likely to lead to similar L2 repertoires. But, importantly for the purposes of the present study, L2 speakers need to incrementally assess the proficiency of their interlocutor, and "[s]uch modelling uses attentional resources and impairs automatic linguistic alignment" (p. 551). L2 users must also evaluate their own planned utterances for comprehensibility to the interlocutor with respect to the interlocutor's assessed proficiency level. The authors furthermore conjecture that an efficient strategy for L2-L2 conversation might be to converge on a reduced grammatical and lexical repertoire that is mutually known to be unproblematic. At its most general, "the relative contributions of [automatic and non-automatic] alignment may be different in second language dialogues from dialogues between native speakers" (Costa et al., 2008, p. 552).

Priming in L2 pedagogy has received ample attention from researchers looking at a range of target structures, in laboratory and classroom settings, e.g., questions (McDonough \& Chaikitmongkol, 2010; McDonough \& De Vleeschauwer, 2012; McDonough \& Kim, 
2009; McDonough \& Mackey, 2006), double-dative constructions (McDonough, 2006), noun and verb morphology (McDonough \& Fulga, 2015), and pronunciation (Trofimovich, McDonough, \& Neumann, 2013). Establishing whether and in what circumstances L2 priming occurs is one question; how it relates to learning is another. One approach to this question is to investigate the relationship between long-term, structural priming and acquisition. A body of research reviewed by Jackson (2017), who defines long-term priming as re-use of a structure encountered not in the immediately preceding sentence but after a longer interval, extending over several sentences but perhaps as much as several weeks, views long-term priming as a type of implicit learning. She identifies a number of factors contributing to the variability of findings - individual differences, discourse context, target structures - but concludes that research on priming during naturalistic conversation is lacking. The current study aims to fill this gap.

\subsection{Alignment during text chat}

Research on alignment in text chat is in its infancy (see Michel \& Smith, 2018, for a recent review). Uzum (2010) builds on a study of alignment in face-to-face tutoring (i.e., Atkinson et al., 2007) by taking a socio-cognitive approach to alignment in text chat. In his qualitative analysis he identifies a number of alignment domains, including interactional speed, lexis and grammar. Collentine and Collentine (2013) use evidence from a corpus involving an online 3D graphical environment and subsequent text chat, finding alignment between Spanish learners on the particular structure under study. Michel and Smith (2018) use eye-tracking to investigate lexical alignment in task-based text chat, and found that while number of gaze fixations on target lexical items was a robust predictor of re-use, two thirds of lexical alignment instances were not accompanied by overtly increased visual attention as measured by fixation data. This might mean, they conclude, that much alignment in SCMC is, after all, prompted by automatic priming. In a study of task-based SCMC in a classroom setting, 
Michel's (2018) secondary-school participants reported in an interview that they were rereading and re-using their interlocutors"' lexical items. Michel suggests this might be linked evidence of strategic alignment. Finally, Michel and Stiefenhofer (2019) examined priming of an advanced structure, the Spanish subjunctive, in classroom and homework SCMC contexts. Although evidence of alignment was limited, they point out that the number of primes provided by informed-confederate participants was low, and that "it is quite surprising that despite this minimal exposure we can see trends of higher creative use, larger creation of obligatory contexts and higher accuracy of subjunctive mood in the priming than the control chat interactions."

It should be noted that, whereas much L2 priming research uses tightly controlled experimental paradigms, the work of Michel and colleagues examine relatively naturalistic contexts in which participants chat during task-based interactions with few constraints. It may well be that some effects found in controlled contexts might not prove robust in real-world situations.

\subsection{Eye-tracking text chat}

The use of chat logs as research data has a long history (e.g., Condon \& Cech, 1996; Herring, 1999). However, increasingly it has been recognised that logs fail to capture much that is of central relevance to SCMC users and to researchers: conversational tempo, drafting processes, off-screen behaviours such as facial expression, gesture, and body language, interaction with other physically co-present peers, and so on (O'Rourke, 2008; Smith, 2008; Smith \& Gorsuch, 2004). Environmental audio and video recordings, video screen-capture, and retrospective interviews are all instruments that can yield richer data relevant to SCMC discourse in general and language learning in particular (e.g., Gurzynski-Weiss \& Baralt, 2015). But eye-tracking promises insights into SCMC user behaviour, and potentially 
cognition, that cannot easily or reliably be derived from any combination of these data sources (Michel \& Smith, 2018).

Eye-tracking, a technique in which the location of gaze is tracked moment-bymoment through recording of eye movements, has been used most prominently in reading and language-processing research (Bax, 2013; Rayner, 2009). Given that the focus of gaze is hypothesized to be related to the current focus of attention, and in particular when the individual is focused on a task with a visual element (the eye-mind association; Just \& Carpenter, 1980), eye-tracking has also received recent attention in second language acquisition and applied linguistics (e.g., Revesz, Michel \& Lee, 2019; Conklin \& PellicerSanchez, 2016; Godfroid, Boers, \& Housen, 2013). A still more recent development is tracking the gaze of learners engaged in online communication (see reviews in Michel \& Smith, 2018). Other work has zoomed in on how learners attend to, and, by inference, process the language produced by themselves and their peers. Smith $(2010,2012)$ examined recasts; Author $(2008,2012)$ looked at monitoring by learners of their own output in relation to message-drafting phases (while-drafting, pre-send, post-send), and identified instances of reuse, re-cast uptake and the use of lexical items as, for example, orthographic models.

The potential of using eye-tracking to investigate alignment in text chat was first recognised by Author and Colleague (2018), reviewed above. Since in text chat the target linguistic expression is visually realised, and the learner's attention to it can be measured in real time using eye-gaze methodology, it is possible to identify cases where a learner is highly likely to be re-using an item produced by the interlocutor given their eye-gaze pattern. This postulated direct link between eye gaze fixations and attention is not without its conceptual and methodological problems, however. To try to overcome uncertainty about attribution of attention to alignment, we will triangulate eye-gaze information with self-report data of participants from post-task cued interviews. In line with earlier work combining eye- 
tracking and stimulated recall (e.g., Godfroid \& Schmidtke, 2013; Smith, 2012), these two data sources are triangulated to investigate attention (through eye-tracking) and awareness (through verbal reports) during text chat. This approach offers us the possibility to contrast the more implicit and automatic processes of eye movements with the more conscious and aware processes reported during interviews. As such, it will be a first step towards answering the question of whether alignment in an L2 is more automatic or more strategic in nature. More specifically, we aim to broaden our understanding about the role of alignment during second language performance in a digitally mediated text chat environment and, accordingly, contribute to that broad research agenda.

\section{Research Questions}

To explore whether alignment in an L2 is, as in L1, based on more automatic and implicit behaviour, or whether the linguistic constraints relate L2 alignment to more strategic choices (as gauged by attention and awareness), the following research questions were asked:

RQ1: To what extent do learners align their lexical choices to those of their partner during L2 text chat?

RQ2: To what extent is lexical alignment related to visual attention, as measured by eyegaze fixations during L2 text chat?

RQ3: To what extent are learners aware that they align to their partner during L2 text chat?

RQ4: What reasons do learners provide for aligning, or not aligning, to their partner?

RQ5: For all these questions we were interested in what role the interactional partner (L2 learning peer vs. native speaker tutor) and language proficiency (B1 to C2) might play.

Following author and colleague (2018) lexical alignment is defined as the reuse of a partner's lexical choices of three or more consecutive words. Table 1 provides an overview of what data and methods will be used to answer the research questions. 
Table 1. Data and methods used to answer RQs

\begin{tabular}{lll}
\hline Research question & Data/Measure & Method \\
\hline RQ 1 & Number of overlapping 3 to 5 grams & Textual analyses of chat- \\
& & logs \\
RQ 2 & Number and duration of eye fixations & Eye-gaze recordings \\
RQ 3 \& 4 & Qualitative comments & Cued interviews \\
RQ 5 & All the above & Comparison Tutor-chat vs. \\
& & Peer-chat \\
\hline
\end{tabular}

\section{Method and Design}

\subsection{Participants}

Twelve English speaking learners of German in higher education participated in the study (cf.

Table 1). The seven females and five males (Age: $\mathrm{M}=21.2, \mathrm{SD}=1.0$; experience studying

German: $\mathrm{M}=9.1$ years, $\mathrm{SD}=2.2$ ) were in their $2^{\text {nd }}, 3^{\text {rd }}$ or $4^{\text {th }}$ year of studying German at university level at time of data collection. Self-rated German proficiency according to CEFR was at B1/B2 (n=2 each), C1 $(n=7)$ and C2 $(n=1)$. Seven students had recently spent time in a German speaking country during an Erasmus exchange. Two German native speakers (first author and research assistant), living in the UK, acted as tutor-interactant in one of the tasks.

Table 2. Participant characteristics

\begin{tabular}{ccccccc}
\hline $\begin{array}{c}\text { Partici } \\
\text { pant }\end{array}$ & Gender & Age & $\begin{array}{c}\text { Years of } \\
\text { German Study }\end{array}$ & $\begin{array}{c}\text { Self-rated } \\
\text { Proficiency }\end{array}$ & L1 & $\begin{array}{c}\text { Erasmus } \\
\text { Study Abroad }\end{array}$ \\
\hline A & f & 21 & 9 & B1 & English & n/a \\
\hline
\end{tabular}




\begin{tabular}{ccccccc}
\hline B & $\mathrm{f}$ & 19 & 8 & $\mathrm{~B} 1$ & English & $\mathrm{n} / \mathrm{a}$ \\
$\mathbf{C}$ & $\mathrm{f}$ & 20 & 9 & $\mathrm{~B} 2$ & English & $\mathrm{n} / \mathrm{a}$ \\
$\mathbf{D}$ & $\mathrm{m}$ & 20 & 6 & $\mathrm{~B} 2$ & English & $\mathrm{n} / \mathrm{a}$ \\
$\mathbf{E}$ & $\mathrm{f}$ & 21 & 10 & $\mathrm{C} 1$ & English & $\mathrm{n} / \mathrm{a}$ \\
$\mathbf{F}$ & $\mathrm{f}$ & 21 & 4 & $\mathrm{C} 1$ & English & 1 year in Germany \\
$\mathbf{G}$ & $\mathrm{m}$ & 22 & 10 & $\mathrm{C} 1$ & English & 8 months in Germany \\
$\mathbf{H}$ & $\mathrm{f}$ & 22 & 11 & $\mathrm{C} 1$ & English & 1 month in Germany \\
$\mathbf{I}$ & $\mathrm{m}$ & 22 & 10 & $\mathrm{C} 1$ & English & 1 year in Germany \\
$\mathbf{J}$ & $\mathrm{m}$ & 22 & 12 & $\mathrm{C} 1$ & English & 8 months in Germany \\
$\mathbf{K}$ & $\mathrm{m}$ & 22 & 10 & $\mathrm{C} 1$ & English & 1 year in Germany \\
$\mathbf{L}$ & $\mathrm{f}$ & 22 & 10 & $\mathrm{C} 2$ & Russian/Polish/ & English since age 8, \\
& & & & & Lithuanian & year in Austria \\
\hline
\end{tabular}

\subsection{Tasks}

Participants performed three communicative tasks using the written chat function of Skype. The first social get-to-know-you task was performed by peers and also served as a familiarisation with the empirical environment, i.e., using Skype text chat in the experimenter's lab. For the second and third task they interacted either with a peer or with a German native speaker tutor. In the peer chat, they were asked to brainstorm and rank a series of measures that might support students in getting to know German locals during an Erasmus study-abroad period. For the tutor chat, they received a selection of photographs and were asked to help their tutor to choose and rank pictures for use in the German department's promotion material (see appendix A).

Participants also answered a short demographic questionnaire targeting their language (learning) background and self-rated proficiency.

\subsection{Apparatus}

Eye movements were tracked by means of a Tobii integrated eye-tracking system using dark pupil tracking. The tasks were presented using Tobii Studio 3.0.9 software 
(https://www.tobii.com). Standardized criteria for the procedure (e.g., 9-point calibration of each eye) and position of the participants (at ca. $60 \mathrm{~cm}$ distance from screen) were followed. Due to availability, one participant worked on a Tobii X2-60 system (sampling rate $60 \mathrm{~Hz}$ ) mounted on a 17" screen Samsung laptop while the other participant was working on a Tobii TX300 (sampling rate $300 \mathrm{~Hz}$ ) on a 23" TFT screen. The entire session was recorded employing the Tobii in-built screen capture feature and user camera. In addition, it measures among others the locus and duration of eye fixations and allows a playback of the participants' eye-gaze during task performance.

\subsection{Design and procedure}

Participants were recruited at the university's German department and invited to three empirical sessions within the same week in exchange for an online shopping voucher.

For the first task, pairs of students arrived at the same time in the researcher's eyetracking lab and were introduced to the study. After signing consent forms, participants were placed in different rooms in front of one of the eye-trackers. After calibration, participants started working on the task. Prompts and instructions were provided on the left, the text chat window on the right half of the computer screen. The font in the chat window had been changed to a 20-point monospace letter type (see Figure 1) and pseudonym chat accounts were used. 


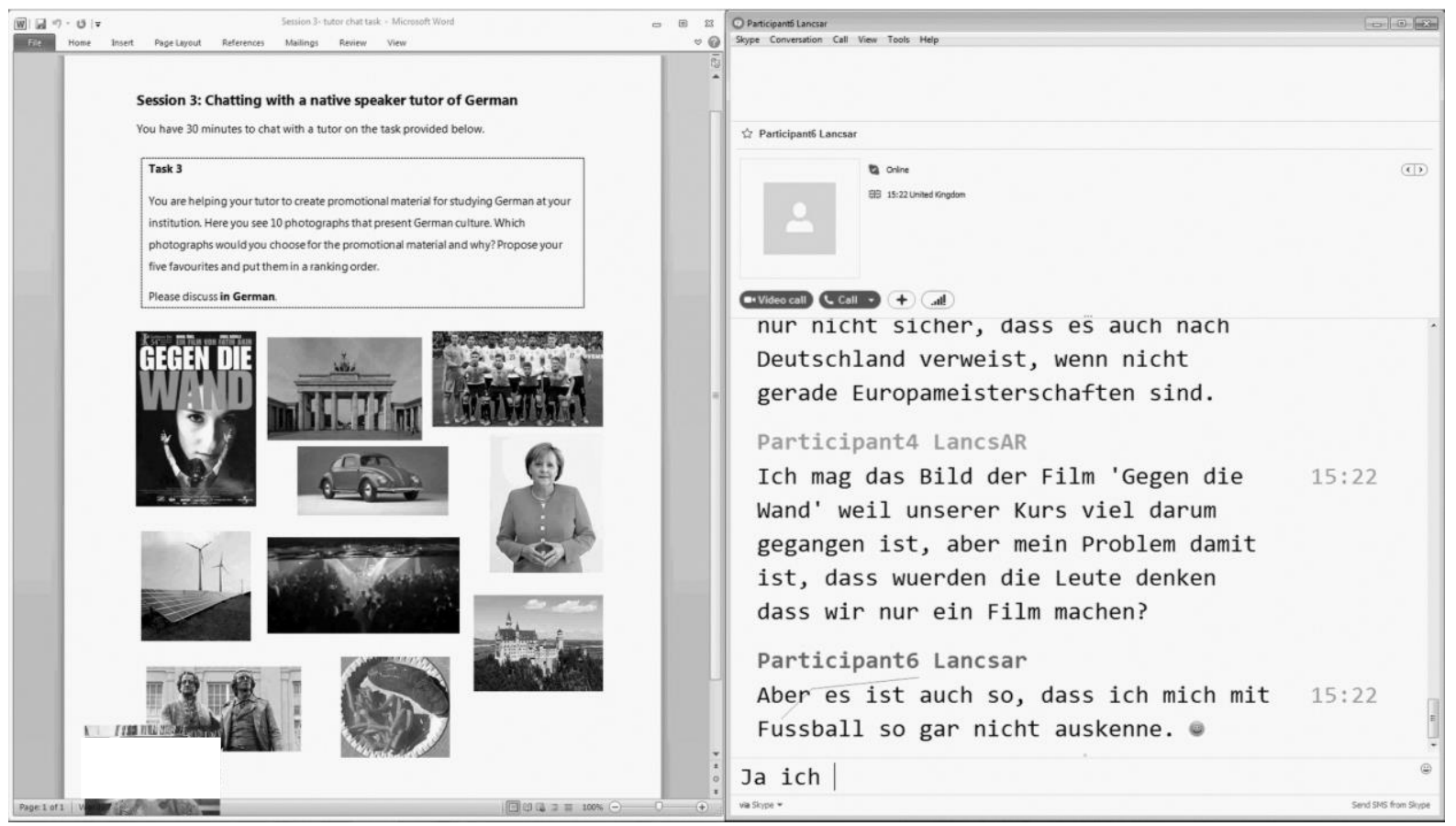

Figure 1. Set-up on the screen with task instruction (left) and Skype chat window (right).

Participants were given one minute to read the instructions, after which they contacted their chat partner and started the 30 minute conversation.

The same procedure was used for the second peer chat, while individual sessions were agreed for the tutor chat. Participants would work on the same eye-tracking system for all three chat sessions. The order of peer- or tutor-chat was counterbalanced over participants. The design of the study is summarised in Figure 2. 


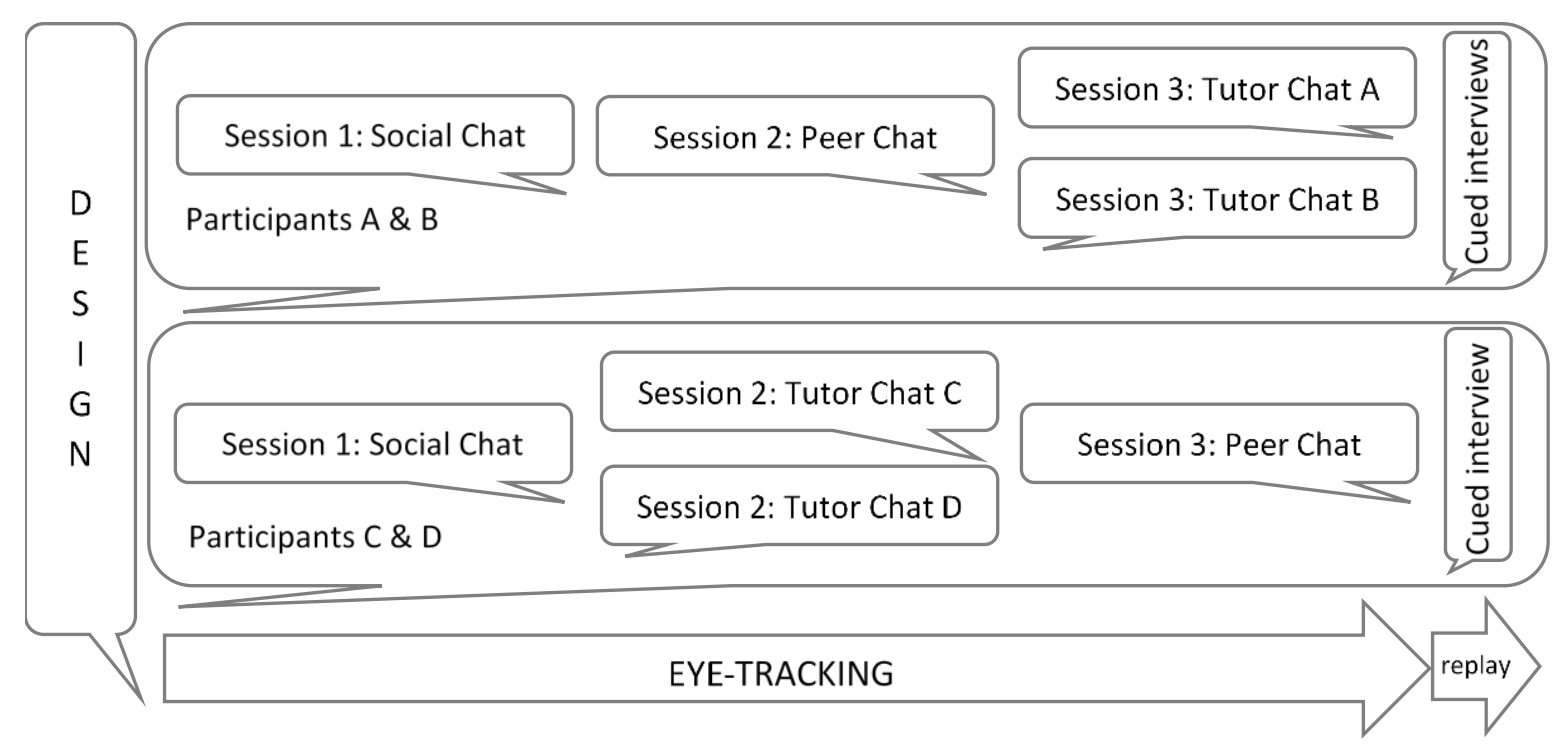

Figure 2. Study design

After the final (peer or tutor) chat session participants had a short break and then took part in an interview cued by a video-replay of their last chat conversation with overlaid eye-gazes. The experimenter explained how to interpret the eye-gazes (e.g., the larger the red dot, the longer you have looked at that position on the screen) and then they were asked to stop the replay and comment each time they identified an episode where they had drawn on the language (e.g., words, phrases, expressions, grammatical aspects such as sentence structure, verb tense, gender agreement) of their partner's contributions. During this first replay, the experimenter took notes of potentially aligned language episodes. During a second replay, the experimenter asked the student to comment on those specific moments. Finally, an open question asked whether a participant thought they had aligned more to the tutor or their peer.

The cued interviews took about an hour and were audio-and-video recorded, with the replay screen in frame so that participants' pointing to the screen would be captured. At the end, participants received debriefing information, words of thanks and an online shopping voucher. 


\subsection{Data coding and analysis}

\subsubsection{Chatlogs}

Chatlogs were copied into spreadsheets and manually edited for minor errors/typos (e.g., Landsknude $\rightarrow$ Landeskunde; beruf $\rightarrow$ Beruf) and transformation of alternative spelling (e.g., aeussere $\rightarrow$ äußere). Following Author and colleague (2018), 3- to 5-grams were identified in each chatlog that appeared at least twice using a free online n-gram analyser (http://guidetodatamining.com/ngramAnalyzer). In the spreadsheet, between-speaker alignment of 3- to 5-grams was then coded manually, if and only if it consisted of exact lexical overlap between two chat partners as exemplified in Extract 1, where "ich stimme zu" would be identified as an aligned 3-gram, while "Leute kennen gelernt" would not be seen as aligned to "Leute kennenzulernen". The rationale for this choice is that we wanted to target alignment at both lexical and structural level.

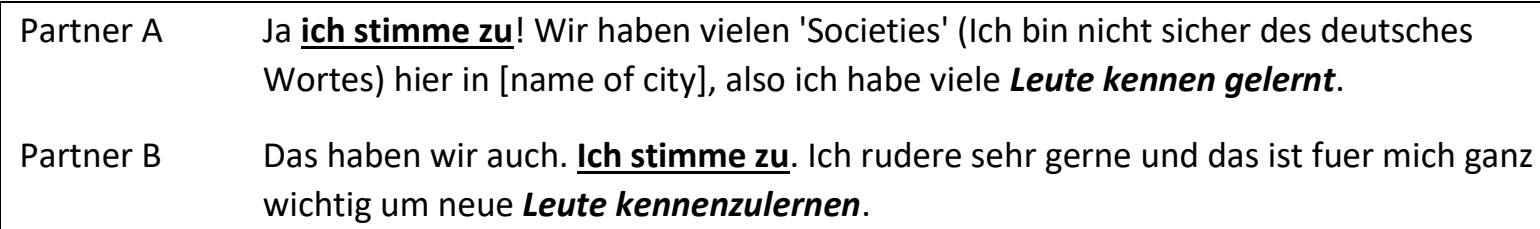

Partner B Das haben wir auch. Ich stimme zu. Ich rudere sehr gerne und das ist fuer mich ganz wichtig um neue Leute kennenzulernen.

Extract 1. Example coding of n-gram alignment

\subsubsection{Eye-gaze data}

For all identified aligned n-grams, eye-gaze data were extracted using Tobii software again following Author and colleague (2018): first, the initial use of an aligned n-gram would be found in the Tobii gaze-replay of the partner. For example, in the replay of participant B the first appearance on screen of the 3-gram 'ich stimme zu' written by participant A was identified as an Area of Interest (AoI). Whenever it changed position (when either partner A or B pressed the enter key), the AoI was deactivated, copied to the new position and reactivated there. This deactivation-copy-reactivation of AoIs was continued until either 
participant B used the same n-gram or the target was pushed out of sight as the conversation filled the screen from below.

Using the Tobii software we extracted the number and total duration of fixations for each aligned n-gram. These raw numbers were normalised for their size expressed by "number of characters including spaces" (Author \& colleague, 2018). For example, the 4gram "Bücher für alle alter" consisting of 21 characters received 7 fixations (normalised: 0.333 fixations per character) for a total duration of 2,569 milliseconds (ms) (normalised: 122 ms per character).

\subsubsection{Cued interview data}

Cued interviews were transcribed verbatim and bottom-up, and thematic coding was applied. Given the qualitative nature of these data, we will refrain from quantifying the findings. Instead, themes will be presented with quotes from these interviews to exemplify participants' reasons for or against alignment.

\section{Results}

The two empirical sessions of all participants resulted in a corpus of 5,286 words and 620 turns for the peer chat interactions and 10,431 words of 946 turns in the tutor chat conversations (total: 15,717 words and 1,566 turns).

\subsection{Chat log analyses: Overlapping n-grams}

Table 2 and Table 3 provide an overview of the chatlog analyses of the peer and tutor chat, respectively, were 24 (peer) and 49 (tutor) overlapping n-grams (total 73) were identified. Most cases of lexical overlap involved 3-grams. When conversing with a peer, average number of aligned n-grams was 3.5, with the tutor just above 4 . 
Table 3. Overlapping n-grams in peer chat

\begin{tabular}{lcccccc}
\hline \multirow{2}{*}{$\begin{array}{l}\text { Pair } \\
\text { Pasmus/ }\end{array}$} & \multicolumn{3}{c}{ Shared n-grams } & \multicolumn{3}{c}{ Counts } \\
\cline { 2 - 7 } & 3-grams & 4-grams & 5-grams & Total & Words & Turns \\
\hline Pre/A-B & 3 & 1 & 1 & 5 & 859 & 69 \\
Pre/A-C & 3 & 4 & 1 & 8 & 851 & 63 \\
Pre/D-substitute & 3 & 0 & 0 & 3 & 362 & 55 \\
Post/F-G & 3 & 0 & 0 & 3 & 958 & 113 \\
Post/H-E & 1 & 0 & 0 & 1 & 843 & 140 \\
Post/J-K & 1 & 0 & 0 & 1 & 541 & 97 \\
Post/L-I & 3 & 0 & 0 & 3 & 872 & 83 \\
\hline Mean & 2.43 & 0.71 & 0.29 & 3.43 & 755 & 88 \\
SD & 0.98 & 1.50 & 0.49 & 2.44 & 217 & 30 \\
\hline Sum & 17 & 5 & 2 & 24 & 5286 & 620 \\
\hline
\end{tabular}

Large individual differences are apparent in conversations irrespective of chat partner (peer

vs. tutor), with some individuals aligning not at all or only once, while others re-use their

partner's word-combinations 8 to 10 times. There seems to be a general trend towards fewer

alignment at higher proficiency levels (before study abroad).

Table 4. Overlapping n-grams in tutor chat

\begin{tabular}{ccccccc}
\hline Erasmus/ & \multicolumn{3}{c}{ Shared n-grams } & & Counts & \\
\cline { 2 - 7 } Participant & 3-grams & 4-grams & 5-grams & Total & Words & Turns \\
\hline Pre/A-tutor & 9 & 1 & 0 & 10 & 994 & 83 \\
Pre/B-tutor & 2 & 2 & 0 & 4 & 883 & 85 \\
Pre/C-tutor & 2 & 1 & 0 & 3 & 958 & 82 \\
Pre/D-tutor & 1 & 1 & 0 & 2 & 468 & 51 \\
Post/E-tutor & 7 & 0 & 0 & 7 & 925 & 73 \\
Post/F-tutor & 7 & 0 & 1 & 8 & 1130 & 103 \\
Post/G-tutor & 7 & 1 & 0 & 8 & 898 & 84 \\
Post/H-tutor & 1 & 0 & 0 & 1 & 538 & 47 \\
Post/I-tutor & 1 & 0 & 0 & 1 & 981 & 92 \\
Post/J-tutor & 4 & 0 & 0 & 4 & 847 & 69 \\
Post/K-tutor & 1 & 0 & 0 & 1 & 592 & 79 \\
Post/L-tutor & 0 & 0 & 0 & 0 & 1217 & 98 \\
\hline Mean & 3.50 & 0.50 & 0.08 & 4.08 & 869 & 79 \\
SD & 3.15 & 0.67 & 0.29 & 3.37 & 229 & 17 \\
\hline Sum & 42 & 6 & 1 & 49 & 10431 & 946 \\
\hline
\end{tabular}




\subsection{Eye-gaze data: fixations on overlapping n-grams}

Table 4 provides an overview of the gaze data during the interactions with a peer vs. tutor.

Out of the 24 overlapping n-grams during the peer chat, gaze data of four participants $(\mathrm{G}, \mathrm{E}$, I, J) did not reveal any fixations on these n-grams. Gaze data of the remaining eight participants on a total of 19 aligned n-grams (79\%) received a median Fixation Count per Character of .333 and a median Total Fixation Duration per Character of above 42 milliseconds.

For the interactions with the tutor, only gaze data of participant L did not yield any fixations. The remaining 11 participants' eye fixations of 24 aligned n-grams (out of the 49 counted overlapping n-grams; 49\%) revealed a median Fixation Count per Character of .471 and a median Total Fixation Duration per Character of 96 milliseconds. Absolute numbers and means mirror this picture. That is, generally there were higher fixation counts as well as longer total fixation times on aligned n-grams provided by the tutor than by a peer.

Given the low sample size and unequal distribution of the gaze data no inferential statistics were calculated.

Table 5. Gaze data on aligned n-grams

\begin{tabular}{ccccccccc}
\hline \multicolumn{4}{c}{ Peer chat } & (19 out of 24 n-grams) & \multicolumn{5}{c}{ Tutor chat (24 out of 49 n-grams) } \\
\hline Fixation \\
Count & $\begin{array}{c}\text { Fixation } \\
\text { Count } \\
\text { /Character }\end{array}$ & $\begin{array}{c}\text { Total } \\
\text { Fixation } \\
\text { Duration } \\
(\mathrm{ms})\end{array}$ & $\begin{array}{c}\text { Total } \\
\text { Fixation } \\
\text { Duration } \\
\text { /Character }\end{array}$ & $\begin{array}{c}\text { Fixation } \\
\text { Count }\end{array}$ & $\begin{array}{c}\text { Fixation } \\
\text { Count } \\
\text { /Character }\end{array}$ & $\begin{array}{c}\text { Total } \\
\text { Fixation } \\
\text { Duration } \\
\text { (sec) }\end{array}$ & $\begin{array}{c}\text { Fotal } \\
\text { Fixation } \\
\text { Duration } \\
\text { /Character }\end{array}$ \\
\hline Mean & 7.632 & .401 & 1252 & 73 & 9.125 & .512 & 1928 & 106 \\
$S D$ & 5.377 & .247 & 985 & 63 & 6.668 & .318 & 1778 & 82 \\
Median & 7 & .333 & 883 & 42 & 7.5 & .471 & 1360 & 96 \\
\hline
\end{tabular}




\subsection{Cued interview data}

Half of the cued interviews were based on the chat interaction with a peer, the other half on the tutor-chat. In the following, we will report on the themes that emerged in either or both groups. Illustrative example quotes for these themes are provided in Appendix B. A first finding is that only a handful of the overlapping n-grams identified in the chatlog analyses were pointed out by the participants during the cued interviews.

\subsubsection{Reasons to align}

All participants stated that they followed the spelling and lexical choices of their partner irrespective of whether this was their peer or tutor. Some students would even scroll back in the chat log to verify a spelling. Regarding lexical choice, students sometimes copied a whole word but many reported re-using a partner's words in an adapted version, for example, drawing on the verb verbinden converted to the noun Verbindung. This adaptation strategy was used for both tutor and peer chat, and particularly characterized students at higher levels of proficiency. Re-use in slightly adapted versions of both lexical and structural choices occurred often in answer to a question or as a counterargument to a point raised. Only a few participants mentioned aligning to morphosyntactic forms. Examples pertain to plural, gender and case marking or infrequent and avoided (verb) forms such as conditionals. Interestingly, two students re-used punctuation. Several participants mentioned that they would align to the style and formality of the language used by their partner and in the peer interactions, a further reason for alignment was to express a relational attitude. This was done by means of discourse markers, emojis and even punctuation.

\subsubsection{Reasons not to align}

The interviews also revealed reasons not to align. For example, two students who believed that their German was at a higher level than that of their partner did not reuse language. One of them instead started recasting her partner's utterances by way of correction. One 
participant thought that having more time to think during text chat, compared to speech, might decrease the amount of alignment.

\subsubsection{Alternative explanations for seemingly aligned text}

Some participants did not remember making conscious choices about text that seemed to have been aligned. Others offered alternative explanations, for example, to avoid a specific German typographic character that wasn't available on the keyboard. Several students reported re-using language from the tutor chat they had engaged in the day before.

\subsubsection{Differences between peer and tutor chat}

In answering the final open question, most participants thought they were aligning more, or in different aspects, with the tutor than with the peer. While two highly proficient participants named it as an explicit strategy, a few participants did not see a difference.

\section{Discussion}

The chat conversations under investigation were analysed using three different data sources, each tapping into a different research question, each of which we will now discuss in turn.

\subsection{Lexical alignment during L2 text chat}

To answer research question 1, to what extent lexical alignment occurs during interaction via text chat, our data show that out of 15,000 words only 73 instances of exact overlapping ngrams were identified in the current chat interactions. Overall, students demonstrated large individual variation in the number of aligned lexical choices (range 0 to 10). It is encouraging that these figures mirror the ones reported by Author and colleague (2018) who identified similarly low numbers of n-grams with exact overlap with large differences ( 0 to 5$)$ between individuals. It is likely that our choice to work with word clusters larger than 3 is responsible for these fairly small numbers. In order to have a workable set of target constructions for the manual eye-gaze coding, we ignored overlap of smaller units (single words or bigrams).

Furthermore, we relied on exact lexical overlap, which excluded instances of partial 
alignment. The latter was a behaviour that many of our participants reported engaging in, for example, copying the root of verbinden to write Verbindung. Future work could explore alignment of both smaller and more abstract units. That is, using natural language processing (NLP) techniques it could be possible to identify lexical overlap at word or even lemma level (cf. Chen \& Meurers, in preparation; Wang \& Wang, 2015), which would allow to gain a better insight into this phenomenon. Follow-up analyses could also compare the use of syntactic constructions (cf. Dao, Trofimovich \& Kennedy, 2018) which would allow us to investigate whether alignment took place at a more structural level. Given the low numbers reported here, it is questionable whether lexical alignment plays an important role during text-based digital communication in an L2.

\subsection{Attention for lexical choices: eye-gaze data on aligned n-grams}

Our second research question aimed to explore whether lexical alignment is related to visual attention as measured by eye-gaze fixations during L2 text chat. Similar to Author and colleague (2018), only a subset of the aligned n-grams received measurable attention (i.e., $80 \%$ in the peer chat and $50 \%$ in the tutor chat). Yet looking at those that were attended to, eye gaze data of the tutor chat revealed similar numbers of fixations (ca. 2.5 per word) and gaze durations (ca. $530 \mathrm{~ms}$ per word) as for the aligned n-grams identified by Author and colleague (2018; aligned n-grams: 2.5 fixations and 523 ms per word). The average gaze duration in the tutor chat is also higher than the $500 \mathrm{~ms}$ threshold set for noticing in (Smith, 2010). In contrast, peer chat gaze data (ca. 2 fixations and $365 \mathrm{~ms}$ per word) seemed to be closer to the baseline data of Author and colleague (2018: baseline 1.7 fixations and $360 \mathrm{~ms}$ ). In light of this earlier work, we would argue that the aligned n-grams in the tutor chat received substantially more attention than n-grams in the peer chat. This is also more than one would expect based on earlier work measuring normal eye-gaze behaviour when reading messages in a text chat environment. 


\subsection{The role of the interactional partner (peer vs. tutor) and proficiency}

The difference between peer and tutor chat (research question 5) is noteworthy, in particular, when reviewed in relation to Costa et al.'s (2008) conceptualisation of alignment in second language dialogue. Our data support the view that the attention L2 speakers give to their partner's contributions is influenced by whether the partner is a native speaker. That is, participants spent more time and instances of eye-gaze fixations on their partner's input if this was provided by an L1 tutor. The fact that the chatlog analyses also suggest more alignment with the tutor supports this interpretation. It seems, thus, that even though some automatic alignment might happen - as witnessed in the overlapping n-grams found in the peer chat conversations - L2 learners appear to adopt a more voluntary strategy to focus their attention to their interlocutor's input as a model for their own contributions when chatting with a native speaker tutor. Equally, the comments of the cued interviews are in line with this explanation, most clearly expressed by participant L: "I know [the tutor is] the native speaker, so like, obviously I can use this opportunity and pick up words that I might use.” Most participants reported drawing on the tutor's language - even when this had been the day before. In contrast, their peer's input was not mentioned as a source for target language constructions, unless it was clear that there was a substantial difference in perceived language proficiency (cf. pair L-I, where $I$ reports drawing on $L$, while $L$ mentions providing recasts for I). Another example of conscious strategic decisions to (not) use a provided language form comes from participant $\mathrm{A}$, who explains that she wanted to avoid the German letter $\beta$. This interpretation is in line with Kim and McDonough (2008) who found that L1 partners elicited more primed production than peers during oral pedagogic tasks.

A notable tendency found in the current data (i.e., the chatlog analyses) is the general decrease of alignment towards higher levels of proficiency. This suggests that higher level students might not (need to) align as much as lower proficiency level students because they 
have enough resources themselves. Indeed, participant E states " $[\ldots]$ and then I thought, I don't want to keep stealing vocab. [...] But I know I used quite a lot of vocab of her questions and thought: I can do more German than that." In line with earlier work looking at source use during written L2 production (Keck, 2014; Pennycook, 1996) our data suggest that with growing proficiency, L2 writers become more independent from the input. On the other hand, higher level students more often mentioned native speaker models having served as their primary source of input during their learning trajectory. These successful language learners were able to capitalize on the opportunities provided by their context - be it the lyrics of German songs, a flatmate during a stay abroad, or an advertising slogan they had read.

In sum, our data do give support to the interpretation that the interactional partner and native speaker/tutor status impact on L2 speaker's re-use of an interlocutor's language.

\subsection{Awareness about and reasons for/against alignment}

Our third and fourth research questions tapped into awareness of L2 speakers about alignment. That is, we were interested in the extent to which learners noticed that they align to their partner during L2 text chat, and if they did, what reasons they would provide for or against alignment. The cued interview data provided a wealth of information on those matters. Interestingly, most of the participants reported that they would use their partner as a model, but this was restricted to interaction with the tutor. Only a handful of comments identified the exact n-grams that we had found to overlap with their partner. In other words, participants seemed to be aware about alignment as a general strategy but couldn't remember the specific instances in detail. Again, this speaks for the interpretation that, like in L1 discourse, alignment in L2 speaker dialogue has an implicit and likely automatic component that takes place beyond awareness of the L2 speaker (Costa et al., 2008; Pickering \& Garrod, 2004, 2006). 
On the other hand, participants provided many comments confirming strategic behaviour as they reported aligning to their partner at different levels of communication, most prominently lexical choices but also including morphosyntax, pragmatics and - unique to a CMC context - spelling, punctuation and emojis. To the best of our knowledge, our findings are the first to support this hypothesis, which was postulated by others before us (Branigan et al., 2007; Costa et al., 2008; Jackson, 2017; Author \& Colleague, 2018), with empirical evidence.

The cued interviews were crucial in revealing the many strategic decisions L2 speakers take during text chat. The participants provided alternative explanations for seemingly aligned text (e.g., avoidance of a character on a key board) and reasons not to align: "Because I felt like I should perhaps now as a final year student use different vocab" (participant E). Several pointed out that in reacting to a question or argument, it was natural to use the same lexical item in their answer or counterargument. This suggests that different discourse functions might be more prone to alignment than others. Bearing in mind the arguments of Pickering and Garrod (2004), it might mean that some conversations elicit different amounts of linguistic alignment because the discourse context requires more or less alignment of the situational model (e.g., more when trying to find a joint solution than in a pro-contra discussion, c.f., Author \& Colleague, in press).

This study is not without limitations of which the small sample size and heterogeneous group of participants is the most prominent. A further issue concerns our reliance on two different eye-tracking systems for collecting paired interaction data, which might have affected the comparability of the gaze information across participants. We tried to address these shortcomings with design choices (e.g., counterbalancing) and triangulation of different sources of information (chatlogs, eye-gaze data, cued interviews). As a result, our mixed-methods approach provided a very rich data set which allowed us to give valuable 
insights into alignment during L2 speaker dialogue in written digitally mediated communication despite these shortcomings.

\section{Conclusion}

The aim of the present study was to investigate alignment in L2 speaker dialogue with a peer versus native speaker tutor during text chat conversations. Drawing on triangulated data of chatlog analyses, eye-gaze recordings and cued interviews, our findings indicate that both automatic, implicit as well as conscious, strategic processes guided L2 speaker's re-use or dismissal of lexical and other linguistic choices interactants made in task-based conversations.

We would like to highlight some pedagogical implications; most importantly, that text chat is a unique medium of communication, and as a site for L2 written production, deserves a place in the L2 classroom. The combination of implicit, automatic linguistic behaviour and form-focused controlled processes eliciting strategic choices of L2 speakers also suggest that alignment can be used as a pedagogic tool. Earlier work exploring task-based approaches to elicit alignment of advanced L2 structures during text chat conversations reveal small but positive evidence of its value (Author \& Colleague, in press). Our work also implies that we might need to draw L2 learners' attention more explicitly towards the potential for (structural) alignment during conversation even with peers.

There are many future avenues for researching alignment during L2 text chat. One could focus on the role of different interlocutors, e.g., by pairing peers of the same or different proficiency levels with each other and/or with tutors; or students acquainted with each other versus students not acquainted with each other. It also remains underexplored how various socio-cognitive individual differences (e.g., working memory; interaction mindset, Sato, 2017) might affect alignment in both oral and written chat interactions. Finally, as text 
chat is a very prominent type of communication on mobile devices, exploring alignment during mobile text chat would add to ecological validity.

Lastly, we hope that our study adds just a small piece towards the normalisation of technology in language pedagogy (Bax, 2003) and the role of eye-tracking in researching it (Bax, 2013).

\section{References}

Atkinson, D., Churchill, E., Nishina, T., \& Okada, H. (2007). Alignment and Interaction Alignment in a Sociocognitive Approach to Second Language Acquisition. The Modern Language Journal, 91(2), 169-188.

Bax, S. (2003). CALL--past, present and future. System, 31(1), 13-28. https://doi.org/Doi: $10.1016 / \mathrm{s} 0346-251 \times(02) 00071-4$

Bax, S. (2013). The cognitive processing of candidates during reading tests: Evidence from eye-tracking. Language Testing, 30(4), 441-465. https://doi.org/10.1177/0265532212473244

Beauvois, M. H. (1992). Computer-assisted classroom discussion in the classroom: conversation in slow motion. Foreign Language Annals, 25, 455-464.

Branigan, H. P., Pickering, M. J., McLean, J. F., \& Cleland, A. A. (2007). Syntactic alignment and participant role in dialogue. Cognition, 104(2), 163-197. https://doi.org/10.1016/j.cognition.2006.05.006

Chambers, A., \& Bax, S. (2006). Making CALL work: Towards normalisation. System, 34(4), 465-479. https://doi.org/10.1016/j.system.2006.08.001

Chapelle, C. A. (2009). The Relationship Between Second Language Acquisition Theory and Computer-Assisted Language Learning. The Modern Language Journal, 93, 741-753. https://doi.org/10.1111/j.1540-4781.2009.00970.x 
Collentine, J., \& Collentine, K. (2013). A corpus approach to studying structural convergence in task-based Spanish L2 interactions. In K. McDonough \& A. Mackey (Eds.), Second language interaction in diverse educational contexts (pp. 167-188). Amsterdam: John Benjamins.

Condon, S. L., \& Cech, C. G. (1996). Discourse management strategies in face-to-face and computer-mediated decision making interactions. Electronic Journal of Communication/La Revue Électronique de Communication, 6(3).

Conklin, K., \& Pellicer-Sanchez, A. (2016). Using eye-tracking in applied linguistics and second language research. Second Language Research, 1-15. https://doi.org/10.1177/0267658316637401

Costa, A., Pickering, M. J., \& Sorace, A. (2008). Alignment in second language dialogue. Language and Cognitive Processes, 23(4), 528-556. https://doi.org/10.1080/01690960801920545

Doughty, C. J., \& Long, M. H. (2003). Optimal psycholinguistic environments for distance foreign language learning. Language Learning \& Technology, 7(3), 50-80. Retrieved from http://llt.msu.edu/vol7num3/doughty

Engeström, Y. (2014). Learning by expanding. Cambridge: Cambridge University Press.

Gass, S. M., \& Mackey, A. (2006). Input, interaction and output: An overview. AILA Review, 19(1), 3-17. https://doi.org/10.1075/aila.19.03gas

Godfroid, A., Boers, F., \& Housen, A. (2013). An eye for words: Gauging the role of attention in incidental L2 vocabulary acquisition by means of eye-tracking. Studies in Second Language Acquisition, 35(3), 483-517. https://doi.org/10.1017/S0272263113000119

Godfroid, A., \& Schmidtke, J. (2013). What do eye movements tell us about awareness ? A triangulation of eye-movement data, verbal reports, and vocabulary learning scores. 
Noticing and Second Language Acquisition: Studies in Honor of Richard Schmidt, (June), 183-205. Retrieved from http://sls.msu.edu/files/5213/8229/7769/Godfroid_Schmidtke_2013.pdf

Gurzynski-Weiss, L., \& Baralt, M. (2015). Does type of modified output correspond to learner noticing of feedback? A closer look in face-to-face and computer-mediated taskbased interaction. Applied Psycholinguistics, 36(6), 1393-1420. https://doi.org/10.1017/S0142716414000320

Herring, S. (1999). Interactional coherence in CMC. Journal of Computer Mediated Communication, 4(4). Retrieved from http://jcmc.indiana.edu/vol4/issue4/herring.html Jackson, C. N. (2017). Second language structural priming: A critical review and directions for future research. Second Language Research, 0. https://doi.org/10.1177/0267658317746207

Just, M. A., \& Carpenter, P. A. (1980). A theory of reading: From eye fixations to comprehension. Psychological Review, 87(4), 329-354.

Keck, C. (2014). Copying, paraphrasing, and academic writing development: A reexamination of L1 and L2 summarization practices. Journal of Second Language Writing, 25(1), 4-22. https://doi.org/10.1016/j.jslw.2014.05.005

Kim, Y., \& McDonough, K. (2008). Learners' Production of Passives during Syntactic Priming Activities. Applied Linguistics, 29(1), 149-154. https://doi.org/10.1093/applin/amn004

Lai, C., \& Zhao, Y. (2006). Noticing and text-based chat. Language Learning \& Technology, 10(3), 102-120. Retrieved from http://ltt.msu.edu/vol10num3/laizhao/default.html

Lin, W., Huang, H.-T., \& Liou, H.-C. (2013). The effects of text-based SCMC on SLA: A meta analysis. Language Learning \& Technology, 17(2), 123-142. Retrieved from http://lit.msu.edu/issues/june2013/linetal.pdf 
Long, M. H. (1996). The role of the linguistic environment in second language acquisition. In W. C. Ritchie \& T. K. Bhatia (Eds.), Handbook of Second Language Acquisition (pp. 413-468). New York: Academic Press. https://doi.org/10.1016/B978-012589042$7 / 50015-3$

McDonough, K. (2006). Interaction and syntactic priming: English L2 speakers' production of dative constructions. Studies in Second Language Acquisition, 28, 179-207. https://doi.org/DOI: 10+10170S0272263106060098

McDonough, K., \& Chaikitmongkol, W. (2010). Collaborative Syntactic Priming Activities and EFL Learners' Production of Wh -questions. Canadian Modern Language Review, 66(6), 817-841. https://doi.org/10.3138/cmlr.66.6.817

McDonough, K., \& De Vleeschauwer, J. (2012). Prompt-type frequency, auditory pattern discrimination, and EFL learners' production of WH-questions. Studies in Second Language Acquisition, 34(3), 355-377. https://doi.org/10.1017/S0272263112000113

McDonough, K., \& Fulga, A. (2015). The detection and primed production of novel constructions. Language Learning, 65(2), 326-357. https://doi.org/10.1111/lang.12103

McDonough, K., \& Kim, Y. (2009). Syntactic priming, type frequency, and EFL learners' production of wh-questions. Modern Language Journal, 93(3), 386-398. https://doi.org/10.1111/j.1540-4781.2009.00897.x

McDonough, K., \& Mackey, A. (2006). Responses to recasts: Repetitions, primed production, and linguistic development. Language Learning, 56(4), 693-720. https://doi.org/10.1111/j.1467-9922.2006.00393.x

Michel (2018) Practising online with your peers: The role of text chat for second language development C. Jones (Ed.), Practice in second language learning, Cambridge: Cambridge University Press (2018), pp. 164-196

Michel \& Smith (2018) Measuring lexical alignment during L2 chat interaction: An eye- 
tracking study S.M. Gass, P. Spinner, J. Behney (Eds.), Salience in second language acquisition, Routledge, London (2018), pp. 244-267.

Michel \& Stiefenhoefer (2019) Priming Spanish subjunctives during synchronous computermediated communication: German peers' classroom-based and homework interactions. M. Sato, S. Loewen (Eds.), Evidence-based second language pedagogy: A collection of Instructed Second Language Acquisition studies, Routledge, New York (2019)

O'Rourke (2008) The other C in CMC: What alternative data sources can tell us about synchronous computer mediated communication and language learning. Computer Assisted Language Learning, 28 (3), 227-251

O'Rourke (2012) Using eye tracking to investigate gaze behaviour in synchronous computermediated communication for language learning. M. Dooly, R. O’Dowd (Eds.), Researching online interaction and exchange in foreign language education: Methods and issues, Peter Lang,, Frankfurt am Main (2012), pp. 305-341Pennycook, A. (1996). Borrowing others' words: Text, ownership, memory, and plagiarism. TESOL Quarterly, 30(2), 201. https://doi.org/10.2307/3588141

Pickering, M. J., \& Ferreira, V. S. (2008). Structural Priming: A Critical Review. Psychological Bulletin, 134(3), 427-459. https://doi.org/10.1037/00332909.134.3.427.Structural

Pickering, M. J., \& Garrod, S. (2004). Toward a mechanistic psychology of dialogue. Behavioral and Brain Sciences, 27(2), 169-190. https://doi.org/doi:10.1017/S0140525X04000056

Pickering, M. J., \& Garrod, S. (2006). Alignment as the basis for successful communication. Research on Language and Computation, 4(2-3), 203-228.

https://doi.org/10.1007/s11168-006-9004-0

Plonsky, L., \& Ziegler, N. (2016). The CALL-SLA interface: Insights from a second-order 
synthesis. Language Learning \& Technology, 20(2), 17-37. Retrieved from http://www.lltjournal.org/item/2945

Rayner, K. (2009). Eye movements and attention in reading, scene perception, and visual search. The Quarterly Journal of Experimental Psychology, 62(8), 1457-1506.

Retrieved from http://www.informaworld.com/10.1080/17470210902816461

Sauro, S. (2011). SCMC for SLA: A Research Synthesis. CALICO Journal, 28(2), 369-391. https://doi.org/Report

Sauro, S., \& Smith, B. (2010). Investigating L2 performance in text chat. Applied Linguistics. https://doi.org/10.1093/applin/amq007

Schmidt, R. (1990). The role of consciousness in second language learning. Applied Linguistics, 11, 129-158.

Smith, B. (2008). Methodological hurdles in capturing CMC data: the case of the missing self-repair. Language Learning \& Technology, 12(1), 85-103. Retrieved from http://lit.msu.edu/vol12num1/smith/default.html

Smith, B. (2010). Employing eye-tracking technology in researching the effectiveness of recasts in CMC. In F. M. Hult (Ed.), Directions and Prospects for Educational Linguistics (pp. 79-97). London: Springer.

Smith, B. (2012). Eye tracking as a measure of noticing: A study of explicit recasts in SCMC. Language Learning \& Technology, 16(3), 53-81. https://doi.org/http://hdl.handle.net/10125/44300

Smith, B., \& Gorsuch, G. J. (2004). Synchronous computer mediated communication captured by usability lab technologies: new interpretations. System, 32(4), 553-575. Retrieved from http://www.sciencedirect.com/science/article/B6VCH-4DTKX014/2/af33bd6f5857b284bd94f1fd0ffc25ef

Trofimovich, P., McDonough, K., \& Neumann, H. (2013). Using collaborative tasks to elicit 
auditory and structural priming. TESOL Quarterly, 47(1), 177-186.

https://doi.org/10.1002/tesq.78

Uzum, B. (2010). An investigation of alignment in CMC from a sociocognitive perspective. CALICO Journal, 28(1), 135-155.

Wang, C., \& Wang, M. (2015). Effect of Alignment on L2 Written Production. Applied Linguistics, 36(5), 503-526. https://doi.org/10.1093/applin/amt051

Wertsch, J. V. (2002). Computer mediation, PBL, and dialogicality. Distance Education, 23(1), 105-108.

https://doi.org/10.1080/01587910220124008org/10.1080/01587910220124008

Ziegler, N. (2016). Synchronous Computer-Mediated Communication and Interaction.

Studies in Second Language Acquisition, 38(3), 553-586.

https://doi.org/10.1017/S027226311500025X 


\section{Appendix A: Tasks}

\section{Social Task: Getting to know your partner}

You have 30 minutes to get to know your partner a bit better.

Task 1. Try to collect the following information from your partner. In turn, you will be asked to chat a bit about yourself and your studies. Please ask and answer all the questions in German.

- Name

- Age

- Gender: male / female

- Mother tongue / cultural background

- What is your partner studying?

- In what year? What are her/his major/minor subjects?

- Why did your partner chose to study German?

- What does your partner like or dislike most about German?

- Did your partner ever live in a German speaking country?

- If yes, where and for how long?

- Ask some more details about this experience, e.g., What did your partner like or dislike about it? (If she/he didn't live there, is this a dream? What would she/he expect?)

- Anything else you want to know and ask... 


\section{Peer task: Chatting with a partner participant}

You have 30 minutes to chat with your partner participant on the task provided below.

Peer Task. You are part of a committee supporting students going to Germany on Erasmus exchange. A known challenge facing many Erasmus students is getting to know local German students. Together, you will brainstorm five measures that can help students to integrate into German student life. At the end of the chat, please provide your joint five ranked measures.

\section{Tutor task: Chatting with a native speaker tutor of German}

You have 30 minutes to chat with your partner participant on the task provided below.

Tutor Task. You are helping your tutor to create promotional material for studying German at your institution. Here you see 10 photographs that present German culture. Which photographs would you choose for the promotional material and why? Propose your five favourites and put them in a ranking order. Please discuss in German. 


\section{Appendix B. Thematic analysis of cued interviews - sample quotations}

Table B1. Reasons to align

\begin{tabular}{|c|c|}
\hline Target & Example comment \\
\hline Spelling & $\begin{array}{l}\text { "Yes, to get the spelling of Organisation and unterrichten. Looking back } \\
\text { to know how many 'r's." (Participant A, scrolling back to partner's use) }\end{array}$ \\
\hline $\begin{array}{l}\text { Lexical choice } \\
\text { - exact copy }\end{array}$ & $\begin{array}{l}\text { "So, here the use of Solarzellen. I couldn't remember what the word was } \\
\text { for them, }[\ldots] \text { so I started copying that out here, so that was directly as a } \\
\text { result of what was above [written by the tutor]." (Participant J) }\end{array}$ \\
\hline $\begin{array}{l}\text { Lexical choice } \\
\text { - adaptation }\end{array}$ & $\begin{array}{l}\text { "I remember that I picked that up [verbinden written by tutor] to use it } \\
\text { later on but then changed it to Verbindung." (Participant H) }\end{array}$ \\
\hline $\begin{array}{l}\text { Lexical choice } \\
\text { - adaptation as reaction } \\
\text { peer chat }\end{array}$ & $\begin{array}{l}\text { "okay here, this is a direct copy of her language [Participant F uses Es } \\
\text { zahlt, weil... Participant G answers zu dieser aufgabe zahlt] - it counts. } \\
\text { Doesn't count - it counts. Just a contradiction. It comes straight from her } \\
\text { use of this verb here". (Participant G) }\end{array}$ \\
\hline $\begin{array}{l}\text { Lexical choice } \\
\text { - adaptation as reaction } \\
\text { tutor chat }\end{array}$ & $\begin{array}{l}\text { "I'd been debating using aussuchen I think, but then used waehlen } \\
\text { because that had been asked. [...] I thought, that's the verb that's been } \\
\text { used in the question so it's safest to go with that just in case there are } \\
\text { some slight differences in meaning." (Participant E) }\end{array}$ \\
\hline $\begin{array}{l}\text { Morphosyntax } \\
\text { - case marking }\end{array}$ & $\begin{array}{l}\text { "Yeah, I never know whether it is Dir or Dich and I always use the } \\
\text { wrong one. Eh so, I'm just going to take it off the other person" } \\
\text { (Participant A) }\end{array}$ \\
\hline $\begin{array}{l}\text { Morphosyntax } \\
\text { - verb tense }\end{array}$ & $\begin{array}{l}\text { "Waere, I'd say came from her use of it, }[\ldots] \text { from her use of conditional } \\
\text { before", and a few minutes later "So here with wollte, I am trying to kind } \\
\text { of match her tense." (Participant I) }\end{array}$ \\
\hline Punctuation & $\begin{array}{l}\text { "Because I distinctly remember I was going to write two points/period } \\
\text { and then she, her use of that [comma] reminded me that Germans use } \\
\text { comma for that kind of thing quite often" (Participant I). }\end{array}$ \\
\hline $\begin{array}{l}\text { Style/Formality } \\
\text { - tutor }\end{array}$ & $\begin{array}{l}\text { "I just noticed there [tutor wrote: ja, ich glaube, dass } \underline{d u} \text { das richtig } \\
\text { aufgelistet hast] as well was the use of } D u \text { and Sie, cause beforehand I } \\
\text { didn't know which one to use." (Participant J) }\end{array}$ \\
\hline $\begin{array}{l}\text { Style/Formality } \\
\text { - peer }\end{array}$ & $\begin{array}{l}\text { "In the prior study [with the tutor] I've use the ae construction and stuff } \\
\text { like that for those umlauts. But because participant F uses quite } \\
\text { colloquial language towards the end I just give up on umlauts." } \\
\text { (Participant G) }\end{array}$ \\
\hline $\begin{array}{l}\text { Relation/rapport } \\
\text { - discourse marker }\end{array}$ & $\begin{array}{l}\text { "I know I definitely used genau in this one because she had said it in the } \\
\text { last one" (Participant C) }\end{array}$ \\
\hline $\begin{array}{l}\text { Relation/rapport } \\
\text { - emoji }\end{array}$ & "yes, I used the emoji purely because she did" (Participant A) \\
\hline $\begin{array}{l}\text { Relation/rapport } \\
\text { - punctuation }\end{array}$ & $\begin{array}{l}\text { "So here, my exclamation point on mine is definitely a reaction to her } \\
\text { using it in hers" (Participant G) }\end{array}$ \\
\hline
\end{tabular}


Table B2. Reasons not to align

\begin{tabular}{|c|c|}
\hline Target & Example comment \\
\hline $\begin{array}{l}\text { Proficiency } \\
\text { - recasting }\end{array}$ & $\begin{array}{l}\text { "Yeah, I replied na ja as well, he used the same, right. Also, because I'm } \\
\text { not sure if it's written separately or together, so I... cause I sort of went } \\
\text { through all my, in all of my German chats I would use it separately, so I } \\
\text { kind of like I guess unconsciously corrected." (Participant L). }\end{array}$ \\
\hline $\begin{array}{l}\text { Proficiency } \\
\text { - unnatural }\end{array}$ & $\begin{array}{l}\text { "because I often think that maybe his doesn't sound that natural." } \\
\text { (Participant F) }\end{array}$ \\
\hline Processing ease & $\begin{array}{l}\text { "But I think definitely when I'm speaking I'm more inclined to use the } \\
\text { things that they say because it then is at the forefront of your mind then. } \\
\text { When you're writing, I think you think a lot more about it so I don't } \\
\text { think it would have that much of an influence." (Participant G) }\end{array}$ \\
\hline
\end{tabular}

Table B3. Alternative explanations

\begin{tabular}{|c|c|}
\hline Aim & Example comment \\
\hline Avoid German character & $\begin{array}{l}\text { Regarding the seemingly aligned phrase ich bin instead of the earlier } \\
\text { used ich heiße: "I think it is actually to not use the scharfes } s[\beta] . " \\
\text { (Participant A) }\end{array}$ \\
\hline Remember from tutor chat & $\begin{array}{l}\text { "In the chat yesterday they've used Ich stimme } z u \text {. I think she [peer] used } \\
\text { it as well [indeed - two minutes earlier] Obviously, I knew the phrase but } \\
\text { I never use it myself, I'd always say du hast recht I never say ich stimme } \\
z u \text { so this was because I remembered it from yesterday - with the tutor." } \\
\text { (Participant A) }\end{array}$ \\
\hline Remember from tutor chat & $\begin{array}{l}\text { II remember using things today that the tutor has said yesterday." } \\
\text { (Participant B) }\end{array}$ \\
\hline
\end{tabular}

Table B4. Differences between peer and tutor chat

\begin{tabular}{ll}
\hline Reason & Example comment \\
\hline Grammatical vs. lexical & "I would say that it is probably it was more lexical with the girl \\
& yesterday, um, possibly more grammatical this time [with the tutor]." \\
& (Participant C) \\
"I used the language of the tutor a lot more [...] If I can use things that & are given to me. We always were taught at school, use the vocab, use \\
& whatever you can find and you can build on that." (Participant E) \\
"When I know that somebody that I'm chatting that's a native speaker \\
[...] I tend to pick up language more." (Participant L) \\
: "I used but then reused the phrases in a slightly different way. I don't \\
think I did this very differently today than with a peer yesterday" \\
(Participant H).
\end{tabular}


